\title{
Diagnostic Stability of Psychiatric Disorders in Baqiyatallah Hospital from 1997 to 2015
}

\author{
Seyed Abbas Tavalaei ${ }^{1}$, Shervin Assari ${ }^{2}$, Vahid Tavalaei ${ }^{3}$, Roghieh Nooripour ${ }^{4}$, * \\ ${ }^{1}$ Behavioral Sciences Research Center, Baqiyatallah University of Medical Sciences, Tehran, IR Iran \\ ${ }^{2}$ Department of Psychiatry, School of Medicine, University of Michigan, Ann Arbor, USA \\ ${ }^{3}$ Counseling, Department of Counseling, Faculty of Psychology \& Education, Ardekan University, Yazd, IR Iran \\ ${ }^{4}$ Counseling Department, Faculty of Psychology \& Education, Alzahra University, Tehran, IR Iran
}

*Corresponding Author: Roghieh Nooripour, Counseling Department, Faculty of Psychology \& Education, Alzahra University, Tehran, IR Iran. Tel: +98-9118187318, Fax: +98-2185692580, Email: nooripour.r@gmail.com

Received: 16 Jun. 2016; Accepted: 20 Jul. 2016; Online Published: 27 Aug. 2016

\begin{abstract}
Background: Hospitalization compared to outpatient care leads to better diagnosis. Stability of diagnosis varies among different psychiatric disorders and is associated with some demographic and mental health variables.

Objective: The current study evaluated the stability of diagnosis in Baqiyatallah Hospital Psychiatric Ward.

Methods: In this retrospective study, 908 inpatient records from the psychiatric ward of Baqiyatallah Hospital in the years 1997-2015 were randomly selected. Having primary and final diagnoses was the inclusion criterion. Demographic variables (age, sex, marital status, education, and employment) and mental health variables (primary and final psychiatric diagnoses, duration of hospitalization, psychiatric history, and medication history) were recorded. Ultimately, 429 cases were entered into the study.

Results: The overall diagnostic stability rate was $57.6 \%$. In mood, anxiety, psychotic, and personality disorders, the diagnostic stability rates were $84 \%, 63.8 \%, 46.3 \%$, and $36.4 \%$, respectively. For depressive and bipolar disorders, the stability of diagnosis rates were $85.5 \%$ and $86 \%$, respectively. A significant relation between diagnosis axis, number of diagnoses, drug abuse and somatic disease history and diagnostic stability was seen $(\mathrm{p}<0.05)$.

Conclusion: According to the present study, the maximum diagnostic stability rate was related to mood disorders with anxiety disorders ranking second. The minimum stability was related to personality disorders. Other studies have reported completely different results which may be due to different situations. Future studies in this field seem to be essential.
\end{abstract}

Keywords: Diagnosis, Psychiatry, Hospitals

\section{Background}

Oversight or error in diagnosis leads to insufficient intervention and treatment in many patients, and this delays disease improvement [1]. Diagnosis error and changes in diagnosis were attributed to diversity of psychiatric symptoms, disorder similarity, the different course of each disease, and comorbid disorders. In many instances, a diagnosis is not possible until extensive medical and psychological evaluation has taken place [2]; therefore, it is essential that psychiatrists use diagnostic sources other than symptoms [3].

In some cases, patients are hospitalized in a psychiatric ward not only for treatment, but also for diagnosis. Inpatient admission may be valuable in clarifying diagnoses. Improvement in diagnosis after hospitalization is attributed to the accurate observation of the patient, the use of diagnostic tests and imaging (because of access to a laboratory and radiology), and more neuro-psychological examinations [4]. Therefore, it can be claimed that hospitalization may lead to a better psychiatric diagnosis. Over one-third of ICD-10 F20 schizophrenia cases at three years had non-schizophrenia diagnoses at onset [5]. Patients with manic symptomatology at the beginning had a very unstable and changeable course [6]. A survey of patients admitted four or more times to the same acute care psychiatric hospital over a period of 3 years revealed that only $34 \%$ of such patients were discharged with the same diagnosis on each admission [7]. In another study, the diagnosis index of nearly half of patients changed over a 4year period [8]. It was found that the percentage of patients with changed diagnoses is highest at first readmission; at each later readmission, the diagnosis of manic-depressive psychosis changed in about $10 \%$ of bipolar and $25 \%$ of unipolar cases, and a similar number of diagnoses was changed from other diagnoses to manic-depressive psychosis [9]. During a two-year observation period, half of patients were readmitted, and the stability of diagnosis rate was $60 \%$ [10].

In approximately $56 \%$ of patients, the initial diagnosis of depressive disorder eventually changed during follow-up mainly to disorders in the schizophrenia spectrum (16\%), but also to personality disorders $(9 \%)$, neurotic, stress-related, and somatoform disorders (8\%), and bipolar disorder (8\%). Among the $18 \%$ of patients who were later diagnosed with depressive disorder, $23 \%$ were initially diagnosed with adjustment disorder [11], and $46.4 \%$ of hospitalized patients had at least one previous hospitalization with a psychiatric diagnosis other than bipolar disorder [12]. A large proportion of inpatients had their diagnoses altered, especially during hospitalization [13].

\section{Objective}

This study evaluated the diagnostic stability of psychiatric disorders at Baqiyatallah Hospital. 


\section{Methods}

In this retrospective study, 908 psychiatry ward inpatient records from Baqiyatallah hospital were randomly selected from all records throughout the years 1996-2015. Having primary and final diagnoses was the inclusion criterion. Demographic variables (age, sex, marital status, education, employment), mental health variables (primary and final psychiatric diagnoses, duration of hospitalization, psychiatric history, and medication history) were recorded. Ultimately, 429 cases were entered into the study.

Stability of diagnosis was studied in cases including those with unchanged diagnoses from admission to discharge. The groups diagnosed were mood disorders, anxiety disorders, psychotic disorders, and personality disorders. The axis I diagnosis was divided into mood disorders, anxiety disorders, psychotic disorders, and other disorders. Personality disorders were all considered to be axis II diagnoses. The psychiatric diagnoses and diagnostic axis were recorded separately.

Data input and statistical analysis were accomplished using SPSS software. To describe the qualitative variables, frequency and relative frequency tables were used; to describe quantitative variables, mean, median, standard deviation, etc. were used.

Descriptive Statistics (frequency, percentage) and diagnostic analysis, which is a kind of regression analysis, were used to analyze data $(\mathrm{P}<0.05)$.

\section{Results}

In this study, the overall stability of diagnosis rate in hospitalized patients was $57.6 \%$ (Table 1). Diagnoses in order of stability were: mood disorders (84\%), anxiety disorders (63.8\%), psychotic disorders (46.3\%), and personality disorders $(36.4 \%)$.

Diagnostic stability rates were $37(86 \%)$ and $213(85.5 \%)$ for bipolar disorder and depressive disorder, respectively (Table 2).

The stability of diagnosis showed no significant relation with marital status, education, being a soldier or official employee, suicidality, smoking, malingering, economical problems, electro-convulsion therapy $(\mathrm{ECT})(\mathrm{p}>0.05)$ (Table 3).

Table 1. Descriptive statistics for early diagnoses of mood, anxiety, psychotic, and secondary character recognition

\begin{tabular}{|cc|}
\hline Secondary Diagnosis & Frequency (\%) \\
\hline Mood disorders $(\mathbf{n}=\mathbf{3 1 2})$ & $262(84)$ \\
\hline Mood disorders & $39(12.5)$ \\
Anxiety disorders & $30(9.6)$ \\
Personality disorders & $23(7.4)$ \\
\hline Psychotic disorders & \\
\hline Anxiety disorders $(\mathbf{n}=\mathbf{5 8})$ & $37(63.8)$ \\
\hline Anxiety disorders & $39(66.1)$ \\
\hline Mood disorders & $2(3.4)$ \\
\hline Personality disorders & $4(6.9)$ \\
\hline Psychotic disorders & \\
Psychotic disorders $(\mathbf{n}=\mathbf{1 0 8})$ & $50(46.3)$ \\
\hline Psychotic disorders & $58(52.3)$ \\
\hline Mood disorders & $3(2.8)$ \\
\hline Anxiety disorders & $10(9.3)$ \\
Personality disorders & \\
\hline Personality disorders $(\mathbf{n}=\mathbf{1 2})$ & $4(36.4)$ \\
\hline Personality disorders & $6(50)$ \\
\hline Mood disorders & $1(9.1)$ \\
\hline Anxiety disorders & $1(9.1)$ \\
\hline Psychotic disorders & \\
\hline
\end{tabular}

Table 2. Descriptive statistics for stability of diagnosis in bipolar and depression secondary diagnoses

\begin{tabular}{|cc|}
\hline Secondary Diagnosis & Frequency (\%) \\
\hline Bipolar $(\mathbf{n}=\mathbf{4 3})$ & \\
Bipolar disorder & $37(86)$ \\
Depression & $3(7)$ \\
Anxiety disorders & $1(2.3)$ \\
\hline Psychotic disorders & $8(18.6)$ \\
\hline Personality disorders & $0(0)$ \\
Depression $(\mathbf{n}=\mathbf{2 4 9})$ & \\
\hline Depression & $213(85.5)$ \\
\hline Bipolar disorder & $9(15.3)$ \\
\hline Anxiety disorders & $38(15.3)$ \\
\hline Psychotic disorders & $15(6)$ \\
\hline Personality disorders & $29(11.6)$ \\
\hline
\end{tabular}

Table 3. Diagnostic stability relationship and variables

\begin{tabular}{|lccc|}
\hline Variable & $\begin{array}{c}\text { Diagnostic } \\
\text { Stability }\end{array}$ & $\begin{array}{c}\text { Diagnostic } \\
\text { Instability }\end{array}$ & Sig. \\
\hline Age & $29.90 \pm 9.86$ & $26.05 \pm 8.51$ & 0.000 \\
Marital status & $131(53)$ & $24(50)$ & 0.090 \\
\hline Education level & $47(20)$ & $24(14)$ & 0.140 \\
\hline Soldier box & $95(38.5)$ & $84(46.2)$ & 0.310 \\
Length of stay & $11.97 \pm 8.05$ & $10.15 \pm 7.41$ & 0.001 \\
\hline History of physical illness & $48(21.1)$ & $51(31.1)$ & 0.016 \\
\hline Axis I diagnosis & $244(85.4)$ & $141(77.5)$ & 0.000 \\
$\begin{array}{l}\text { Number of psychiatric } \\
\text { diagnoses equal to 1 }\end{array}$ & $211(85.4)$ & $101(55.5)$ & 0.082 \\
\hline Drug use & $28(12.7)$ & $34(20.7)$ & 0.025 \\
Suicidality & $2(0.8)$ & $1(0.5)$ & 0.071 \\
\hline Simulation & $2(0.8)$ & $0(0)$ & 0.602 \\
\hline Smoking & $119(53.8)$ & $83(50.3)$ & 0.109 \\
\hline Economic problems & $111(50.5)$ & $90(56.3)$ & 0.082 \\
\hline Undergoing ECT & $70(28.3)$ & $44(24.2)$ & 0.430 \\
\hline Data in table are present
\end{tabular}

Data in table are presented as Mean SD or No. (\%).

\section{Discussion}

In this study, the diagnostic stability (DS) for mood disorders was $84 \%$. In another study, the DS for mood disorders was $68 \%$ [14]. The DS for mood disorders 5 years after the primary diagnosis was $40 \%$ [15], and the $30-40$ year follow-up of mood disorders showed DS to be $78.3 \%$ [6]. In another report, the DS for mood disorders was $67 \% .28 .9 \%$ of subjects with an initial diagnosis of BPD had their diagnoses changed, whereas $16.1 \%$ of subjects with non BPD diagnoses had their diagnoses changed to BPD at a later episode [16].

The DS for anxiety disorders in this study was $63.8 \%$. Results of another study showed that anxiety disorders had the greatest DS [17]. In yet another study, anxiety disorders had the lowest diagnostic stability rate [18].

The current study determined the DS for psychotic disorders to be $46.3 \%$. Two other studies determined the DS of schizophrenia to be $74 \%$ and $67 \%$ [19]. In another study, patients with an initial episode of schizophrenic psychosis showed the greatest DS (93\%) [4]. Psychotic disorder was the most stable. Among schizophrenic patients, higher stability rates appeared for residual and disorganized types [20].

In the current study, disturbed personality showed $36.4 \%$ DS. Two other studies, however, reported a $36 \%$ and a $73 \%$ DS for disturbed personality [14]. $12.5 \%$ of evaluated patients with borderline personalities had the same diagnosis at their first consultation as 5 years afterwards [21]. Dysthymic disorder was more frequently changed to major depressive episode than any other disorder [22]. The 6-12 month follow-up of schizotypal, borderline, avoidant, and obsessive-compulsive patients and the group of major depressive disorder patients (as control group) showed that more subjects in each personality disorder group remained at a diagnostic threshold throughout the 12-month follow-up 
period than did those in the major depressive disorder group, although the number of criteria present decreased over time in all groups [23]. Another study tracked the individual criteria of DSM-IV personality disorders - borderline, schizotypal, avoidant, and obsessive-compulsive personality disorders - and how they changed over 2 years. This study showed that the most prevalent and least changeable criteria over 2 years were paranoid ideation and unusual experiences for schizotypal personality disorder, affective instability and anger for borderline personality disorder, feeling inadequate and feeling socially inept for avoidant personality disorder, and rigidity and problems delegating for obsessivecompulsive personality disorder. The least prevalent and most changeable criteria were odd behavior and constricted affect for schizotypal personality disorder, self-injury and behaviors defending against abandonment for borderline personality disorder, avoiding jobs that are interpersonal and avoiding potentially embarrassing situations for avoidant personality disorder, and miserly behaviors and strict moral behaviors for obsessive-compulsive personality disorder [24].

\subsection{Classification of Different Psychological Disorders Based on Diagnostic Stability}

In the current study, mood disorders and personality disorders had the most and least diagnostic stability, respectively. Anxiety disorders and psychotic disorders were between these ranges of stability. Different studies in this field have shown different results. In one study, high levels of stability were found for schizophrenia, moderate levels for affective disorders, low levels for other non-organic psychotic conditions and atypical psychosis, and very low levels for schizoaffective disorder and other conditions [25]. In another study, the highest diagnostic stability was found in patients with a diagnosis index of alcohol abuse, schizophrenia, and drug abuse, while the lowest stability was found in patients with neurotic, hysterical, and depressive disorders, acute psychoses, and bipolar disorders [26]. The most temporally consistent 6-month categories were schizophrenia, bipolar disorder, and major depression; the least stable were psychosis not otherwise specified, schizoaffective disorder, and brief psychosis [27]. In one study, schizophrenia and mania were the most stable diagnoses and organic disorders had the most variable diagnoses [28]. In another study, mobility was most marked for the neurosis group and was approximately uniform for other groups [29].

In the current study, a significant relation was identified between stability of diagnosis and diagnosis axis, number of diagnoses, drug abuse, and somatic disease history. Stability of diagnosis showed no significant relation with marital status, education, being a soldier or official employee, suicidality, smoking, malingering, economical problems, or electro-convulsion therapy. Age, gender, ethnicity, substance abuse, and disease severity had prominent roles in diagnostic changes; however, one study found no variables associated with diagnostic instability apart from the diagnoses themselves [30].

\section{Conclusion}

According to the present study, the highest diagnostic stability rates were found in affective disorders and anxiety disorders, respectively. The least diagnostic stability rate was found for personality disorders; in $50 \%$ of these patients, the diagnosis was changed to affective disorder. The variables of substance abuse and organic disease history were related to the instability of diagnosis. Future prospective studies in this field will be of assistance.

\section{Acknowledgements}

The authors would like to thank the "Clinical Research Development Unit" of Baqiyatallah Hospital for their kind cooperation.

\section{Authors' Contributions}

SAT, ShA were involved in designing the study; ShA, SVT, and RN were involved in data analysis; SAT, SVT, and $\mathrm{RN}$ were involved in manuscript preparation.

\section{Conflict of Interest}

None.

\section{References}

1. Kim JE, Saw A, Zane NW, Murphy BL. Patterns of utilization and outcomes of inpatient psychiatric treatment in Asian Americans. Asian Am J Psychol. 2014;5(1):35-43. doi: 10.1037/a0034439

2. Bewernick BH, Kayser S, Sturm V, Schlaepfer TE. Long-term effects of nucleus accumbens deep brain stimulation in treatment-resistant depression: evidence for sustained efficacy. Neuropsychopharmacology. 2012;37(9):1975-85. doi: 10.1038/npp.2012.44

3. Kroll M, Carpenter L, Murphy M, Stiller C. Effects of changes in diagnosis and registration on time trends in recorded childhood cancer incidence in Great Britain. Br J Cancer. 2012;107(7):1159-62. doi: 10.1038/bjc.2012.296

4. Zhang T, Good M-JD, Good BJ, Chow A, Wang L, Dai Y, et al. Age and remission of personality pathology in the psychotic disorders compared to mood and/or anxiety disorders. Int J Psychiatry Med. 2012;44(3):241-55. doi: 10.2190/PM.44.3.e

5. Dutta R, Murray RM, Allardyce J, Jones PB, Boydell J. Early risk factors for suicide in an epidemiological first episode psychosis

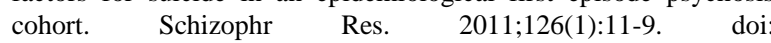
10.1016/j.schres.2010.11.021

6. Möller H, Jäger M, Riedel M, Obermeier M, Strauss A, Bottlender R. The Munich 15-year follow-up study (MUFUSSAD) on firsthospitalized patients with schizophrenic or affective disorders: assessing courses, types and time stability of diagnostic classification. Eur Psychiatry. 2011;26(4):231-43. doi: 10.1016/j.eurpsy.2010.04.012

7. Simpson GM, Glick ID, Weiden PJ, Romano SJ, Siu CO. Randomized, controlled, double-blind multicenter comparison of the efficacy and tolerability of ziprasidone and olanzapine in acutely ill inpatients with schizophrenia or schizoaffective disorder. Am J Psychiatry. 2004;161:1837-47. doi: 10.1176/ajp.161.10.1837

8. Fusar-Poli P, Cappucciati M, Rutigliano G, Heslin M, Stahl D, Brittenden Z, et al. Diagnostic stability of ICD/DSM first episode psychosis diagnoses: Meta-analysis. Schizophr Bull. 2016. pii:sbw020. doi: 10.1093/schbul/sbw020

9. Strejilevich S, Martino D, Murru A, Teitelbaum J, Fassi G, Marengo E, et al. Mood instability and functional recovery in bipolar disorders. Acta Psychiatr Scand. 2013;128(3):194-202. doi: 10.1111/acps. 12065

10. Albert N, Bertelsen M, Thorup A, Petersen L, Jeppesen P, Le Quack $\mathrm{P}$, et al. Predictors of recovery from psychosis: analyses of clinical and social factors associated with recovery among patients with firstepisode psychosis after 5years. Schizophr Res. 2011;125(2):257-66 doi: 10.1016/j.schres.2010.10.013

11. Mataix-Cols D, Frost RO, Pertusa A, Clark LA, Saxena S, Leckman JF, et al. Hoarding disorder: a new diagnosis for DSM-V? Depress Anxiety. 2010;27(6):556-72. doi: 10.1002/da.20693

12. Roshanaei-Moghaddam B, Katon W. Premature mortality from general medical illnesses among persons with bipolar disorder: a review. Psychiatr Serv. 200960(2):147-56. doi: 10.1176/appi.ps.60.2.147

13. Omer S, Golden E, Priebe S. Exploring the Mechanisms of a PatientCentred Assessment with a Solution Focused Approach (DIALOG+) in the Community Treatment of Patients with Psychosis: A Process Evaluation within a Cluster-Randomised Controlled Trial. PloS One. 2016;11(2):e0148415. doi: 10.1371/journal.pone.0148415

14. Guzzetta F, Miglio R, Santone G, Picardi A, Norcio B, Bracco R, et 
al. First-ever admitted psychiatric inpatients in Italy: clinical characteristics and reasons contributing to admission: findings from a national survey. Psychiatry Res. 2010;176(1):62-8. doi 10.1016/j.psychres.2008.11.005

15. Schulz JB, Boesch S, Bürk K, Dürr A, Giunti P, Mariotti C, et al Diagnosis and treatment of Friedreich ataxia: a European perspective. Nat Rev Neurol. 2009;5(4):222-34. doi: 10.1038/nrneurol.2009.26

16. Haas M, DelBello MP, Pandina G, Kushner S, Van Hove I, Augustyns I, et al. Risperidone for the treatment of acute mania in children and adolescents with bipolar disorder: a randomized, double-blind, placebo-controlled study. Bipolar Disord 2009;11(7):687-700. doi: 10.1111/j.1399-5618.2009.00750.x

17. Carballo JJ, Baca-Garcia E, Blanco C, Perez-Rodriguez MM, Arriero MAJ, Artes-Rodriguez A, et al. Stability of childhood anxiety disorder diagnoses: a follow-up naturalistic study in psychiatric care. Eur Child Adolesc Psychiatry. 2010;19(4):395-403. doi 10.1007/s00787-009-0064-1

18. Lenzenweger MF. Current status of the scientific study of the personality disorders: an overview of epidemiological, longitudinal, experimental psychopathology, and neurobehavioral perspectives. J Am Psychoanal Assoc. 2010;58(4):741-78. doi: 10.1177/0003065110386111

19. Atwoli L, Ndambuki D, Owiti P, Manguro G, Omulimi N. Short-term diagnostic stability among re-admitted psychiatric in-patients in Eldoret, Kenya. Afr J Psychiatry (Johannesbg). 2012;15(2):114-8. doi: 10.4314/ajpsy.v15i2.15

20. Huguelet P, Schneider El Gueddari N, Glauser D. Stability of DSMIII-R diagnoses: Study of a case register. Psychopathology. 2001;34(3):118-22. doi: 10.1159/000049293

21. Skodol AE, Gunderson JG. Personality disorders and mood disorders: perspectives on diagnosis and classification from studies of longitudinal course and familial associations. J Pers Disord. 2010;24(1):83. doi: 10.1521/pedi.2010.24.1.83

22. Shankman SA, Lewinsohn PM, Klein DN, Small JW, Seeley JR, Altman SE. Subthreshold conditions as precursors for full syndrome disorders: a 15-year longitudinal study of multiple diagnostic classes. J Child Psychol Psychiatry. 2009;50(12):1485-94. doi 10.1111/j.1469-7610.2009.02117.x
23. Sanislow CA, Little TD, Ansell EB, Grilo CM, Daversa $M$ Markowitz JC, et al. Ten-year stability and latent structure of the DSM-IV schizotypal, borderline, avoidant, and obsessivecompulsive personality disorders. J Abnorm Psychol. 2009;118(3):507. doi: 10.1037/a0016478

24. Schirmbeck F, Rausch F, Englisch S, Eifler S, Esslinger C, MeyerLindenberg A, et al. Stable cognitive deficits in schizophrenia patients with comorbid obsessive-compulsive symptoms: a 12-month longitudinal study. Schizophr Bull. 2013;39(6):1261-71. doi: 10.1093/schbul/sbs123

25. Keshavan MS, Morris DW, Sweeney JA, Pearlson G, Thaker G, Seidman LJ, et al. A dimensional approach to the psychosis spectrum between bipolar disorder and schizophrenia: the Schizo-Bipolar Scale. Schizophr Res. 2011;133(1):250-4. doi 10.1016/j.schres.2011.09.005

26. Bromet EJ, Kotov R, Fochtmann LJ, Carlson GA, Tanenberg-Karant M, Ruggero C, et al. Diagnostic shifts during the decade following first admission for psychosis. Am J Psychiatry. 2011;168(11):118694. doi: 10.1176/appi.ajp.2011.11010048

27. Schwartz JE, Fennig S, Tanenberg-Karant M, Carlson G, Craig T, Galambos N, et al. Congruence of diagnoses 2 years after a firstadmission diagnosis of psychosis. Arch Gen Psychiatry. 2000;57(6):593-600. doi: 10.1001/archpsyc.57.6.593

28. Lavigne JV, LeBailly SA, Gouze KR, Binns HJ, Keller J, Pate L. Predictors and correlates of completing behavioral parent training for the treatment of oppositional defiant disorder in pediatric primary care. Behav Ther. 2010;41(2):198-211. doi 10.1016/j.beth.2009.02.006

29. Castellini G, Sauro CL, Mannucci E, Ravaldi C, Rotella CM, Faravelli C, et al. Diagnostic crossover and outcome predictors in eating disorders according to DSM-IV and DSM-V proposed criteria: a 6-year follow-up study. Psychosom Med. 2011;73(3):270-9. doi: 10.1097/PSY.0b013e31820a1838

30. Amminger GP, Henry LP, Harrigan SM, Harris MG, AlvarezJimenez M, Herrman H, et al. Outcome in early-onset schizophrenia revisited: findings from the Early Psychosis Prevention and Intervention Centre long-term follow-up study. Schizophr Res. 2011;131(1):112-9. doi: 10.1016/j.schres.2011.06.009 